\title{
Ciclagem de nutrientes em diferentes condições topográficas em Floresta Estacional Semidecidual, Pinheiral-RJ
}

\author{
Nutrient cycling in different topographic conditions in Semideciduous Forest, \\ Pinheiral - RJ state
}

\begin{abstract}
Gilsonley Lopes dos Santos ${ }^{\mathrm{I}}$, Marcos Gervasio Pereira ${ }^{\mathrm{II}}$, Thais de Andrade Corrêa Neto ${ }^{\mathrm{III}}$, Victória Maria Monteiro Mendonça ${ }^{\mathrm{IV}}$, Carlos Eduardo Gabriel Menezes ${ }^{\mathrm{V}}$
\end{abstract}

\begin{abstract}
Resumo
Nos ecossistemas florestais, a dinâmica da serapilheira está relacionada à tipologia vegetal e as condições climáticas dos ambientes, as quais são influenciadas pela heterogeneidade topográfica da paisagem. Assim, o objetivo deste estudo foi avaliar se diferentes condições de relevo (pedoformas convexa e côncava) alteram a dinâmica da serapilheira em Floresta Estacional Semidecidual na sub-bacia do ribeirão Cachimbal, PinheiralRJ. Foram selecionadas duas pedoformas adjacentes com relevo do tipo convexa (convexa-divergente) e côncava (côncava-convergente), sendo essas divididas em minissítios (MS) I, II, e III na pedoforma convexa e IV, V e VI na pedoforma côncava. Nos diferentes ambientes foram avaliados o estoque e a decomposição da serapilheira em duas estações do ano (chuvosa e seca). Para avaliar o estoque foram coletadas dez amostras de serapilheira de cada um dos MS, utilizando um gabarito quadrado com $25 \mathrm{~cm}$ de lado. Para avaliar a taxa de decomposição da serapilheira, foram selecionadas $10 \mathrm{~g}$ de folhas, as quais foram acondicionadas em litterbags, instalados no campo e coletadas em diferentes intervalos de tempo. O estoque e os teores de nutrientes da serapilheira foram influenciados em função do tipo da pedoforma, variação do gradiente topográfico e estação do ano, maiores estoques foram observados na pedoforma convexa, em estação seca e os maiores teores de $\mathrm{K}^{+}$e $\mathrm{Mg}^{+2}$ foram observados nos MS inferiores das pedoformas. Por outro lado, os teores de carbono foram influenciados apenas pela estação do ano como maiores teores na estação chuvosa. A decomposição da serapilheira ocorre de maneira diferenciada em função da pedoforma, do gradiente topográfico e da estação do ano, cujos maiores valores foram observados na pedoforma convexa e na estação chuvosa.
\end{abstract}

Palavras-chave: Serapilheira; Decomposição; Ecossistemas florestais

\begin{abstract}
In forest ecosystems the dynamics of burlap is related to the plant typology and to the climatic conditions of environments, which are influenced by the topographic heterogeneity of the landscape. The objective of this study was to evaluate whether different relief conditions (convex and concave pedoforms) alter the burlap dynamics in a semi-deciduous seasonal forest in the sub-basin of Cachimbal, Pinheiral - RJ state. Two adjacent landforms with relief convex type (convex-divergent) and concave (concave-convergent) were selected, and these ones were divided into mini sites (MS) I, II, and III in the convex landform and IV, V and VI in the concave landform. The stock and the decomposition of the burlap in two seasons (rainy and dry) were rated in different environments. To evaluate the stock, ten samples of litter from each MS were collected using a square template with $25-\mathrm{cm}$ side. To evaluate the burlap decomposition rate, $10 \mathrm{~g}$ of leaves were selected, which were placed in litterbags, installed in the field and collected at different time intervals. Litter stock and nutrient contents were influenced by the pedoform type, topographic gradient variation and season, larger stocks were observed in convex pedoform in dry season and higher $\mathrm{K}^{+}$and $\mathrm{Mg}^{+2}$ contents. in the lower pedoform MS. On the other hand, the carbon contents were influenced only by the season of the year like higher contents in the rainy season. The decomposition of burlap forming material occurs differently depending on the landform, topographic gradient and on the season, where the highest values were observed in the convex landform and in the rainy season.
\end{abstract}

Keywords: Litter; Decomposition; Forest ecosystems

\footnotetext{
Engenheiro Florestal, Dr., Pós Doutorando do Programa de Pós-Graduação em Ciências Ambientais e Florestais da Universidade Federal Rural do Rio de Janeiro, BR 465 Seropédica, CEP 23851-970, Rio de Janeiro (RJ), Brasil. leylopes85@hotmail.com (ORCID: 0000-0002-5329-647X)

Engenheiro Agrônomo, Dr., Professor Titular da Universidade Federal Rural do Rio de Janeiro, BR 465 Seropédica, CEP 23851-970, Rio de Janeiro (RJ), Brasil. gervasio@ufrrj.br (ORCID: 0000-0002-1402-3612)

III Engenheira Florestal, Drª -, Pesquisadora autônoma, Rua Alfredo Volpi nº50 apto. 705, Recreio dos Bandeirantes, CEP 22790-600, Rio de Janeiro (RJ), Brasil. tacneto@gmail.com (ORCID: 0000-0003-1752-1526)

IV Engenheira Florestal, MSc., Doutoranda do Programa de Pós-Graduação em Ciências Ambientais e Florestais da Universidade Federal Rural do Rio de Janeiro, BR 465 Seropédica, CEP 23851-970, Rio de Janeiro (RJ), Brasil. viic_monteiro@hotmail.com (ORCID: 0000-0003-0136-2962)

Licenciado em Ciências Agrícolas, Dr., Professor Titular do Instituto Federal de Educação, Ciência e Tecnologia Rio de Janeiro, R. José Breves, 550, Bairro Centro, CEP 27197-000, Pinheiral (RJ), Brasil. carlos.menezes@ifrj.edu.br (ORCID: 0000-0001-8092-2491)
} 


\section{Introdução}

Atualmente existem muitos parâmetros quali e quantificadores da ciclagem de nutrientes em ecossistemas florestais, entre eles está a serapilheira. Os níveis de estoque e fluxo de nutrientes estão relacionados com a produção e deposição da mesma, pois a deposição é relacionada à tipologia vegetal e às condições climáticas dos ambientes (SCORIZA et al., 2014).

Os teores de nutrientes na serapilheira são influenciados pelas condições de solo da vegetação, da composição florística, das características das espécies vegetais quanto à absorção, utilização e redistribuição dos nutrientes e a idade das árvores (RIGGS et al., 2015). Assim, as espécies vegetais possuem um papel fundamental na ciclagem de nutrientes e nas alterações dos atributos físicos e químicos do solo, por meio dos processos de deposição e decomposição da serapilheira (CUNHA et al., 2009).

A serapilheira nos ambientes florestais é composta por material de origem vegetal proveniente da floresta os quais podem ser estratificados como folhas, flores, ramos, cascas, raízes e sementes. Em menor proporção, podem apresentar também material de origem animal como, resíduos animais e material fecal depositado na superfície do solo (CUNHA NETO et al., 2013).

Após o aporte do material formador da serapilheira, o seu acúmulo na superfície do solo é regulado pela decomposição, etapa essencial da ciclagem de nutrientes (MACHADO et al., 2015; GODINHO et al., 2014). A regulação das taxas de decomposição da serapilheira acumulada depende essencialmente das condições físicas e químicas do ambiente e da qualidade nutricional e orgânica do material aportado (MACHADO et al., 2015; PROTIL et al., 2009).

A decomposição da serapilheira constitui também a principal via de aporte de carbono no solo, sendo então a produção de serapilheira responsável pelo fluxo do ciclo do carbono (JESUS NASCIMENTO et al., 2018; CUNHA et al., 2009). Por outro lado, o teor de carbono na serapilheira acumulada é importante para a definição da relação $\mathrm{C} / \mathrm{N}$, sendo essa relação determinante na qualidade da serapilheira em relação a sua maior ou menor taxa de decomposição e aporte de nutriente no solo (JESUS NASCIMENTO et al., 2018; GODINHO et al., 2014).

O processo de decomposição é dinâmico, no qual ocorre, simultaneamente, a fragmentação física das estruturas, a sua transformação química, a síntese de novos compostos e o transporte dos produtos formados para os horizontes subsuperficiais do solo. (HEAL et al., 1997). Esse processo viabiliza a ciclagem de nutrientes, a qual exerce importante função na reabilitação de áreas degradadas (CUNHA NETO et al., 2013) e é a responsável pelo armazenamento de água no solo (BORÉM e RAMOS, 2002).

A dinâmica da serapilheira na Floresta Atlântica, além da influência das características intrínsecas a vegetação, também é regulada pelas condições topográficas dos ambientes, tais como: elevação, orientação, inclinação e geometria das encostas (pedoformas - côncavas ou convexas) e posição na paisagem (SANTOS, et al., 2017; GODINHO et al., 2013). Pedoformas são modelos de paisagem baseados na curvatura do terreno, conforme estabelecido por Troeh (1965), e podem ser côncavas, retilíneas ou convexas, associando o perfil e a curvatura da paisagem com o grau de intemperismo e evolução do terreno.

Segundo Homeier et al. (2010), a elevação e topografia são mecanismos que provocam mudanças na estrutura da floresta e diversidade florística em florestas tropicais das regiões montanhosas ainda são pouco compreendidos, pois se trata de gradientes indiretos que se correlacionam com diversos fatores ambientais, também inter-relacionados entre si. Diante disso, o objetivo deste estudo foi avaliar se diferentes condições de relevo (pedoformas convexa e côncava) alteram a o estoque, o teor de nutrientes e decomposição da serapilheira em Floresta Estacional Semidecidual sub-bacia do ribeirão Cachimbal, Pinheiral-RJ. 


\section{Material e métodos}

\section{Área de estudo}

O estudo foi realizado no município de Pinheiral, Rio de Janeiro, na região do Médio Paraíba Fluminense, na sub-bacia do ribeirão Cachimbal, que compõe a bacia hidrográfica do rio Paraíba do Sul, localizado entre as latitudes $22^{\circ} 29^{\prime} 03^{\prime \prime}$ e e $22^{\circ} 35^{\prime} 27^{\prime \prime}$ s e entre as longitudes $43^{\circ} 54^{\prime} 49^{\prime \prime}$ W e $44^{\circ} 04^{\prime} 05^{\prime \prime}$ W.

Foram selecionadas duas pedoformas adjacentes com formato do tipo convexo (convexodivergente) e côncavo (côncavo-convergente) com orientação da vertente predominante a sudeste e cobertura vegetal tipo Floresta Estacional Semidecidual Submontana (IBGE, 2012). A cobertura vegetal da área de estudos apresenta fisionomia arbórea de floresta secundária com mais de 60 anos de preservação, com árvores emergentes, sub-bosque já diferenciado formado por espécies esciófilas, grande variedade de espécies lenhosas com DAP e altura elevada, e presença de lianas e epífitas em abundância (MENEZES et al., 2010).

As pedoformas foram segmentadas em três minissítios (MS) diferenciados, quanto ao gradiente topográfico e à declividade, sendo: I (altitude média: $520 \mathrm{~m}$, declividade média: 45\%, largura: $20 \mathrm{~m}$, comprimento: $33 \mathrm{~m}$ ), II (altitude média: $530 \mathrm{~m}$, declividade média: 12\%, largura: $20 \mathrm{~m}$, comprimento: $30 \mathrm{~m}$ ) e III (altitude média: $550 \mathrm{~m}$, declividade média: $26 \%$, largura: $20 \mathrm{~m}$, comprimento: $72 \mathrm{~m}$ ) na pedoforma convexa e IV (altitude média: $485 \mathrm{~m}$, declividade média: 30\%, largura: $20 \mathrm{~m}$, comprimento: $45 \mathrm{~m}$ ), V (altitude média: $590 \mathrm{~m}$, declividade média: 20\%, largura: $20 \mathrm{~m}$, comprimento: $30 \mathrm{~m}$ ) e VI (altitude média: $500 \mathrm{~m}$, declividade média: $32 \%$, largura: $20 \mathrm{~m}$, comprimento: $72 \mathrm{~m}$ ) na pedoforma côncava.

\section{Estoque de serapilheira acumulada}

As coletas da serapilheira acumulada foram realizadas na estação chuvosa (março outubro) e na estação seca (abril a setembro). Foram coletadas dez amostras de cada um dos MS, utilizando um gabarito de $25 \mathrm{~cm}$ de lado $\left(0,0625 \mathrm{~m}^{2}\right)$, arremessado aleatoriamente. A serapilheira acumulada coletada foi acondicionada em sacos plásticos devidamente identificados. Em seguida, depositado em peneira 2,0 mm de malha para eliminar as partículas de solo e de matéria orgânica em estádio avançado de decomposição e fragmentação. Na sequência, foi colocado para secar em estufa de circulação forçada de ar a $65^{\circ} \mathrm{C}$, por $72 \mathrm{~h}$. Posteriormente, o material foi pesado.

A partir da massa seca da serapilheira, foram obtidos os valores de estoque total $(\mathrm{Mg}$ $\mathrm{ha}^{-1}$, por MS. Em seguida, o material foi triturado, quantificando-se os teores de N, P, K${ }^{+}, \mathrm{Ca}^{2+}$ e $\mathrm{Mg}^{2+}$, após digestão sulfúrica (TEDESCO et al., 1995). Já o carbono (C) foi determinado por oxidação a $900^{\circ} \mathrm{C}(\mathrm{CHN}-600$ Carlo Erba EA-1110, Itália).

\section{Decomposição da serapilheira}

A avaliação da decomposição da serapilheira foi realizada em duas épocas estação chuvosa e estação seca. Para a avaliação da taxa de decomposição da serapilheira, foram selecionadas 10 $\mathrm{g}$ de folhas que não apresentavam sinais de decomposição, as folhas foram obtidas pelo método de catação diretamente da serapilheira acumulada no piso florestal. As folhas coletadas foram acondicionadas em sacos de papel devidamente identificados. Na sequência, foi colocado para secar em estufa de circulação forçada de ar a $65^{\circ} \mathrm{C}$, por $72 \mathrm{~h}$. Posteriormente acondicionadas em sacos de polivinil ("litterbags") com malha de $4 \mathrm{~mm}$, área de $25 \mathrm{~cm}$ x $25 \mathrm{~cm}\left(625 \mathrm{~cm}^{2}\right)$ e $1,5 \mathrm{~cm}$ de altura. Em cada um dos MS das pedoformas, foram instalados de forma aleatória 16 litterbags. Os quais foram coletados nos intervalos de 30,60, 90 e 120 dias após a instalação no campo.

A quantificação das taxas de decomposição, ao longo dos períodos de estudo, foi feita 
por meio de medidas de perda de massa, calculando-se a diferença entre a quantidade inicial do material original contido no litterbags (10 g). De posse desses valores, foi estimada a constante de decomposição (k) (equação 01), conforme Thomas \& Asakawa (1993), e o tempo de meia-vida ( $\mathrm{T}^{1 / 2}$ ) (equação 02), segundo Rezende et al. (1999), ambos utilizando o software SIGMAPLOT 8.0.

$$
\mathrm{X}_{\mathrm{t}}=\mathrm{X}_{0}{ }^{*} \mathrm{e}^{\mathrm{kt}}
$$

em que: $\mathrm{X}_{\mathrm{t}}$ é a quantidade de matéria seca ou nutriente remanescente após um período de tempo t, em dias; $\mathrm{X}_{0}$ é a quantidade de matéria seca ou nutriente inicial; e k é a constante de decomposição.

$$
\mathrm{t}_{1 / 2}=\ln (2) / \mathrm{K}
$$

em que: $\mathrm{t}_{1 / 2}$ é o tempo de meia-vida de matéria seca ou nutriente; ln (2) é um valor constante; e k é a constante de decomposição descrita anteriormente.

Foram produzidas também curvas que caracterizam a perda de massa (decomposição) de cada resíduo, com o auxílio do mesmo software. No material remanescente foi avaliada a liberação dos nutrientes, quanto aos teores de N, P e K após digestão sulfúrica (TEDESCO et al., 1995).

\section{Análise dos dados}

Os dados foram submetidos à análise de normalidade (teste de Shapiro Wilk, 5\%) e homogeneidade da variância dos erros (teste de Levene, 5\%). Para os dados que atenderam aos pressupostos estatísticos foi realizada uma análise estatística paramétrica (teste de Tukey, 5\%). Para os dados que não atenderam aos pressupostos estatísticos, foi realizada uma análise estatística não paramétrica (teste de Kruskall-Wallis, 5\%).

\section{Resultados e discussão}

\section{Estoque de serapilheira}

Quanto ao estoque de serapilheira, os maiores valores foram observados na pedoforma convexa e na estação seca (Tabela 1), o que pode estar relacionado às condições ambientais da pedoforma de menor oferta de umidade, devido ao processo de dispersão de água na superfície e subsuperficie e uma maior incidência de radiação solar e ventos (SANTOS et al., 2017).

Estudos como Vital et al. (2004), Portela e Santos (2007) e Godinho et al. (2013), avaliando o estoque de serapilheira em ambientes com floresta, observaram que a maior produção aconteceu no final da estação seca, a qual foi associada ao longo do período de estiagem e a diversidade e estrutura das espécies vegetais do ambiente. Souza et al. (2010), salientam que a maior quantidade de serapilheira acumulada no inverno deve-se à menor atividade biológica na interface serapilheirasolo.

Em contrapartida, para os teores de nutrientes entre as pedoformas, apenas o nitrogênio difere estatisticamente, sendo os maiores teores observados na pedoforma côncava (Tabela 1), possivelmente, devido às diferentes composições da serapilheira acumulada no piso florestal e às condições de relevo das pedoformas. Pois, em estudos realizados por Mendonça et al. (2019), avaliando o aporte de serapilheira em diferentes condições geomorfológicas (pedoformas convexa e côncava) em florestas da mesma região, quantificaram os maiores teores de $\mathrm{N}$ na pedoforma convexa, o que foi correlacionado a uma maior presença de espécies fixadoras de nitrogênio (DINIZ et al., 2015) nesse ambiente, sendo os teores de nutrientes determinados apenas na fração folhas interceptada antes de chegar ao piso florestal, diferentemente desse estudo que incluiu todos os componentes da serapilheira para realização das análises. 
Tabela 1 - Massa seca e teor de nutrientes da serapilheira nas diferentes condições de relevo e estações do ano.

Table 1 - Dry mass and nutrient content of the burlap in different relief conditions and seasons.

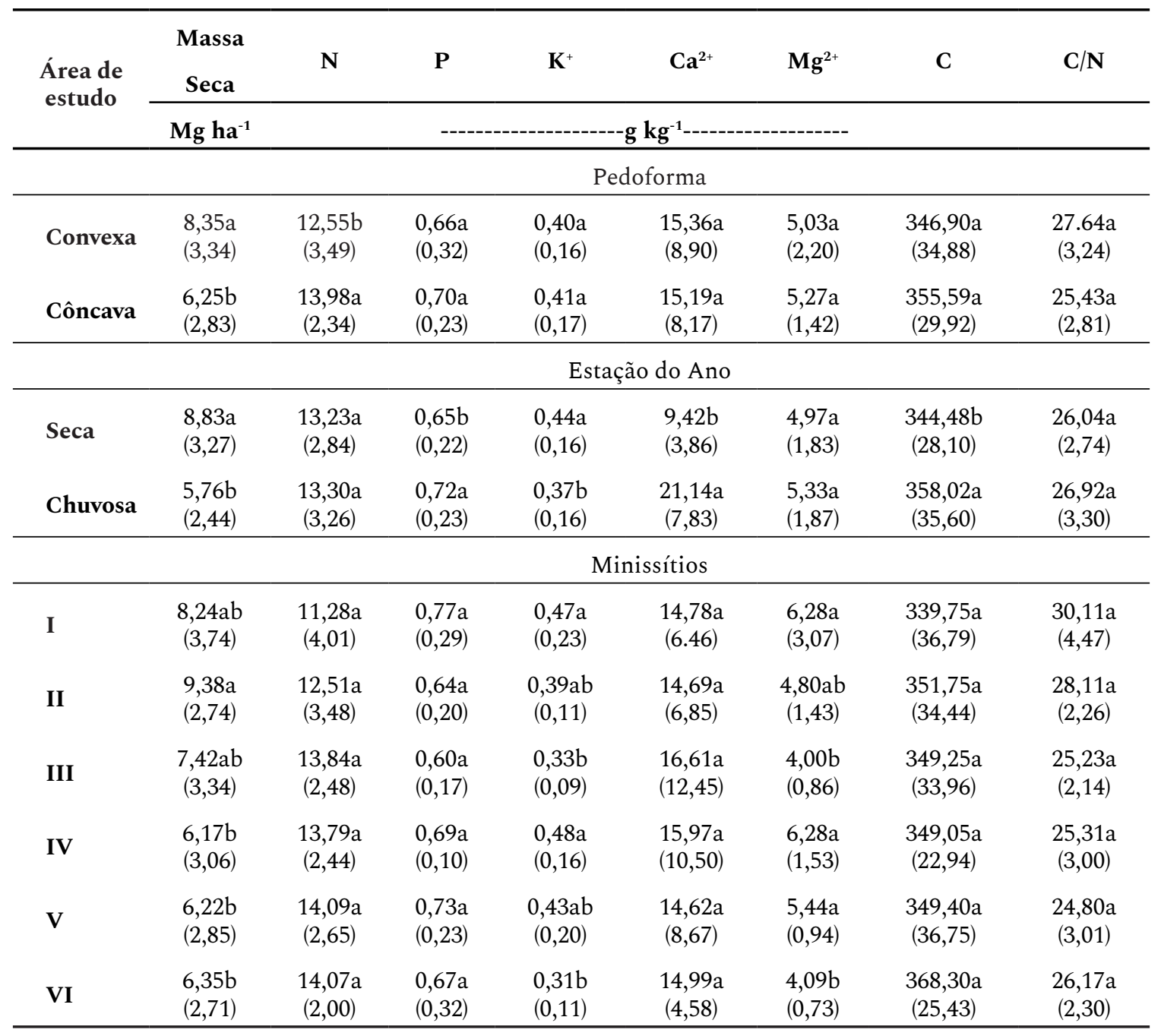

Fonte: Autores (2014)

Em que: Valor entre parentes representa o coeficiente de variação da média.

*Valores seguidos de letras diferentes na coluna, para cada estação do ano, diferem entre $s i(\mathrm{p}<0,05)$, pelo teste de Kruskal-Wallis.

A variação dos teores de nutrientes na serapilheira acumulada entre as pedoformas (Tabela 1), pode estar associada também à composição diferenciada das espécies entre as pedoformas e as condições de relevo. Pois, segundo Cunha et al. (2009), estudando os teores de nutrientes das espécies florestais nativas na Floresta Atlântica, observaram que as espécies apresentam uma capacidade diferenciada de absorver nutrientes do solo, sendo está associada aos fatores como: a taxa de crescimento, o desenvolvimento do sistema radicular e a atividade fisiológica.

Entre as estações do ano foram observadas diferenças para os teores de fósforo, potássio, cálcio e carbono (Tabela 1), sendo os teores de fósforo e cálcio maiores na estação chuvosa e de potássio e carbono maiores na estação seca. Esse padrão pode estar relacionado às mudanças fisiológicas que acontecem na vegetação quanto ao processo de translocação de nutrientes. Protil et al. (2009), ressaltam a ciclagem de nutrientes interna que as plantas realizam, a fim de redistribuir os elementos de tecidos velhos ou senescentes para regiões de meristema ativo antes da queda da serapilheira. 
Os maiores teores de fósforo e cálcio na serapilheira acumulada ao final do período chuvoso podem ser explicados através da liberação mais lenta desses elementos pelo material aportado mais recentemente e a retenção desses nutrientes, que chega com a chuva que atravessa o dossel, pela serapilheira (BORÉM e RAMOS, 2002). Assim, é possível perceber que ambas as pedoformas apresentam maior potencial de reciclagem de $\mathrm{P}$ e Ca no fim do período chuvoso.

Para o potássio, o maior teor encontrado na estação seca é explicado pela facilidade desse elemento ser liberado (lavado) da serapilheira (BORÉM e RAMOS, 2002; VITAL et al., 2004; SCHEER, 2008; GODINHO et al., 2014). Já para o carbono, o maior teor no período seco pode estar relacionado ao maior aporte da serapilheira e menor decomposição, em consequência da menor disponibilidade de água e baixa umidade relativa. Segundo Scheer (2008), as frações menos decompostas ainda devem possuir compostos mais solúveis, como açúcares, amidos e proteínas, que ao longo do tempo são liberados da fitomassa, seja por processos físicos ou pelos organismos decompositores.

Quanto aos MS, pode-se observar que os fatores, curvatura e declividade, influenciaram no estoque e teores de nutrientes da serapilheira, já que o maior valor de estoque de serapilheira acumulada foi observado nos MS da pedoforma convexa, que não diferiram entre si, porém, diferem dos MS da pedoforma côncava que apresentaram menor estoque de serapilheira acumulada (Tabela 1), confirmando os resultados discutidos anteriormente. Mendonça et al. (2019), avaliando o aporte de serapilheira em diferentes condições geomorfológicas, verificaram os maiores valores de aporte para fração folhas e material reprodutivo na pedoforma convexa, sendo esse padrão, associado à maior incidência de luz e ventos, que resulta em um ambiente mais seco, devido às variações microclimáticas das pedoformas ocasionadas por suas feições.

Em relação aos teores de nutrientes, o potássio e o magnésio apresentaram diferenças entre os MS, sendo os maiores teores observados nas partes mais baixas das pedoformas (Tabela 1). Verificando-se uma tendência de diminuição dos valores do MS inferior para o MS superior em ambas as pedoformas, o que provavelmente está relacionado à mobilidade desses nutrientes no solo. Borém e Ramos (2002) observaram padrão similar para ambos os nutrientes $\left(\mathrm{K}^{+}\right.$e $\left.\mathrm{Mg}^{2+}\right)$, determinando elevados valores no final da estação chuvosa nos terços inferiores das topossequências estudadas. Estudos realizados na mesma região constataram a mesma tendência para esses nutrientes, que são de fácil mobilidade no solo, os maiores valores foram observados nas regiões com condições de relevo que permitem o acúmulo de água e maior estoque de serapilheira (DINIZ et al., 2015; MACHADO et al., 2015).

Godinho et al. (2014), quantificando a biomassa e nutrientes na serapilheira acumulada em um trecho de Floresta Estacional Semidecidual Submontana, observaram os menores teores de $\mathrm{K}^{+}$nos meses de abril e maio, e os maiores nos meses de setembro e outubro, meses de maiores e menores precipitações respectivamente. Já para o $\mathrm{Mg}^{2+}$, os autores verificaram uma menor variação nos teores, expressando os maiores valores nos meses de janeiro e outubro e os menores de março a agosto, atribuindo os teores reduzidos à oxidação da clorofila, que ocorre quando as folhas estão em senescência e quando iniciam a decomposição sobre o solo (GODINHO et al., 2014).

Quanto aos teores de C (Tabela 1), a diferença estatística foi observada apenas entre as estações do ano (seca e chuvosa), sendo o maior valor na estação chuvosa. Godinho et al. (2013), avaliando o carbono orgânico na serapilheira depositada em trecho de floresta Semidecidual Submontana, obtiveram resultados similares ao deste estudo, no entanto, os autores chamam atenção que são poucos os estudos relacionados aos teores de nutrientes que observam resultados significativos em relação as estações do ano.

Já a relação $\mathrm{C} / \mathrm{N}$ não apresentou resultados estatisticamente significativos em função das pedoformas, estações do ano (seca e chuvosa) e MS (Tabela 1). Porém, os valores estão próximos aos determinados por outros estudos como Godinho et al. (2014), que variaram de 28,00 a 31,00; e por Borém e Ramos (2002), em Floresta Ombrófila Densa Submontana, variando de 18,00 a 25,00. Valores de relação $\mathrm{C} / \mathrm{N}$ maiores do que 25 indicam que o material foliar apresenta uma baixa proporção de $\mathrm{N}$ (JESUS NASCIMENTO et al., 2018), neste estudo foram observados valores na faixa de 25-30, o que indica uma baixa qualidade nutricional da serapilheira acumulada e essa relação superior a 25 pode ser um fator limitante no processo de decomposição da serapilheira acumulada (JESUS NASCIMENTO et al., 2018). Segundo Godinho et al. (2014), paralelamente à mineralização, ocorre a imobilização de parte dos nutrientes para atender à demanda nutricional dos organismos decompositores, em que o balanço entre esses dois processos é muito complexo e depende da qualidade do resíduo em decomposição, tendo estreita correlação com a relação C/N. 


\section{Decomposição da serapilheira}

Os padrões observados para a decomposição da serapilheira nas pedoformas, nos MS e nas estações chuvosa e seca indicam que o relevo é um dos fatores ambientais determinantes nesse processo, por influenciar diretamente no microclima dos MS, promovendo variações na temperatura e umidade, o que afeta a taxa de deposição e decomposição da serapilheira (Tabela 2) e (Figura 1). Esse padrão também foi observado nos estudos de Borém e Ramos (2002), e Riggs et al. (2015), onde a maior taxa de decomposição e ciclagem de nutrientes ocorreu nos ambientes com maior disponibilidade de umidade do solo.

Na estação chuvosa, os MS I, II e III, localizados na pedoforma convexa apresentaram os maiores valores da constante de decomposição $\mathrm{K}\left(\mathrm{g} \mathrm{g}^{-1} \mathrm{dia}^{-1}\right)$ e consequentemente menor tempo de meia-vida $\mathrm{T}^{1 / 2}$. Padrão oposto foi observado nos MS IV, V e VI da pedoforma côncava (Tabela 1). Na estação chuvosa foram verificados maiores valores de perda de massa seca nos MS I, II e III, sendo que aos 120 dias, no MS II, aproximadamente $50 \%$ da massa total tinha sido decomposta, enquanto no MS IV, a decomposição do material não chegou a $20 \%$.

A maior taxa de decomposição na estação chuvosa está relacionada à combinação das altas temperaturas com a umidade do solo, o que favorece as atividades dos microrganismos decompositores da serapilheira. Ferreira et al., (2014), avaliando a produção e decomposição de serapilheira num fragmento de Floresta Secundária Atlântica de São Paulo, observaram uma correlação forte dos fatores precipitação (chuva) e temperatura com a decomposição da serapilheira, a qual foi associada ao aumento da atividade da fauna do solo em função da maior disponibilidade de água e maior temperatura.

Tabela 2 - alor da constante de decomposição $(K)$, tempo de meia-vida $\left(T^{1 / 2}\right)$, coeficiente de determinação $\left(\mathbf{R}^{2}\right)$, nas diferentes condições de relevo e estações do ano.

Table 2 - Value of the decomposition constant $(\mathrm{K})$, half - life time $\left(\mathrm{T}^{1 / 2}\right)$, coefficient of determination $\left(\mathrm{R}^{2}\right)$, in different relief conditions and seasons.

\begin{tabular}{lccc}
\hline \multicolumn{1}{c}{ Área de Estudo } & Constante $\mathbf{K}\left(\mathrm{g} \mathrm{g}^{-1} \mathbf{d i a}^{-1}\right)$ & $\mathbf{T}^{1 / 2}$ & $\mathbf{R}^{2}$ \\
\hline I & \multicolumn{2}{c}{ Estação Chuvosa } & \\
II & 0,0043 & 161 & 0,97 \\
III & 0,0049 & 141 & 0,99 \\
IV & 0,0047 & 147 & 0,97 \\
V & 0,0018 & 385 & 0,88 \\
VI & 0,0022 & 315 & 0,99 \\
& 0,0032 & 217 & 0,97 \\
\hline I & & & 0,99 \\
II & 0,0014 & 495 & 0,94 \\
III & 0,0012 & 578 & 0,99 \\
IV & 0,0022 & 315 & 0,98 \\
V & 0,0017 & 408 & 0,99 \\
VI & 0,0026 & 267 & 0,99 \\
\hline
\end{tabular}

Fonte: Autores (2014)

Em que: I, II e III - MS com variação do gradiente topográfico e da declividade na pedoforma convexa; IV, V e VI - com variação do gradiente topográfico e da declividade na pedoforma côncava. 
Quanto à estação seca, os maiores valores da constante de decomposição $\mathrm{K}\left(\mathrm{g} \mathrm{g}^{-1}\right.$ dia $^{-}$ 1) foram observados nos MS III, V e VI que estão inseridos nos terços médio e superior das pedoformas, chegando aos 120 dias no MS V aproximadamente $25 \%$ a perda de massa seca. Já nos MS I, II e IV os valores da constante $\mathrm{K}\left(\mathrm{g} \mathrm{g}^{-1} \mathrm{dia}^{-1}\right.$ ) foram menores, ficando próximo a $15 \%$ (Figura 1), portanto, na estação seca a posição do MS na pedoforma foi o fator que mais influenciou no processo de decomposição da serapilheira.

Figura 1 - Curva de decomposição do material foliar nos MS convexo e côncavo com floresta na estação chuvosa $(\mathrm{A})$ e seca $(\mathrm{B})$.

Figure 1 - Decomposition curve of the leaf material in convex and concave MS with forest in rainy and dry season.

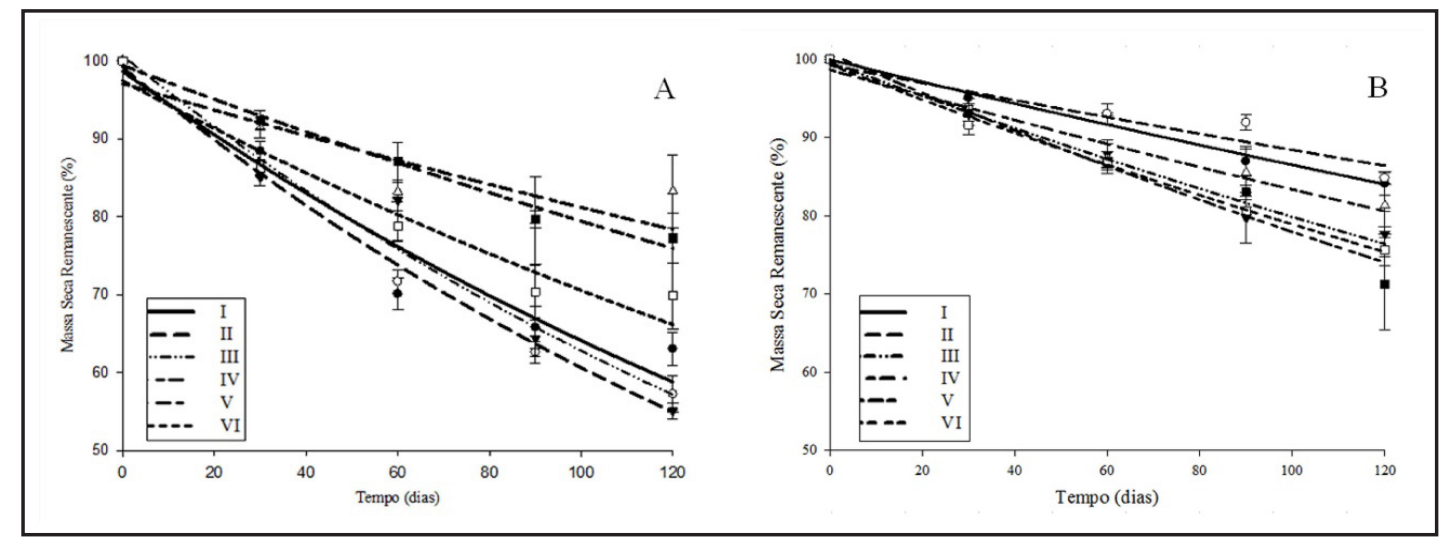

Fonte: Autores (2014)

Os padrões observados na decomposição da serapilheira nos MS e nas estações chuvosa e seca indicam que o relevo é um dos fatores ambientais determinantes nesse processo, por influenciar diretamente no microclima dos MS, promovendo variações na temperatura, na umidade e na composição florística, o que afeta a taxa de decomposição da serapilheira (MACHADO et al., 2011). Influência direta da seca na dinâmica de decomposição da serapilheira em ambiente de floresta, também foi observada por Santonja et al. (2015) que avaliando o efeito da mudança climática na decomposição da serapilheira, verificaram que em períodos longos de seca as taxas de perda de massa foram mais lentas.

As diferenças verificadas para a decomposição da serapilheira foliar nos MS e nas estações do ano pode ser também atribuída às características químicas e físicas do material depositado. Pois, estudos como Scheer et al. (2008) mostram que, dependendo da espécie e da textura da folha, a taxa de decomposição pode ser desfavorecida. Sendo observada também a influência por parte das espécies florestais, a qual está relacionada à formação de diferentes condições ambientais geradas pelas copas das árvores (APONTE et al., 2012).

Por outro lado, em ambientes florestais, a diversidade de espécies proporciona a produção de uma serapilheira foliar mista, com isso, a dinâmica da perda de massa no processo de decomposição da serapilheira foliar é fortemente influenciada pelo conteúdo de nutrientes, a diversidade e atividade da fauna, sendo essa interação muito importante para a ciclagem de nutrientes e a produtividade primária nos ecossistemas florestais (GARTNER et al., 2004). Assim, a variação inter e intraespecífica na qualidade da serapilheira foliar é importante para as taxas de decomposição da serapilheira e mineralização dentro de um sítio florestal (HATTENSCHWILER, 2005).

A dinâmica do processo de decomposição da serapilheira (folhas) observada nesse estudo permite inferir que a variação do tipo da pedoforma, a estação do ano e o gradiente topográfico 
são determinantes na ciclagem de nutrientes e influenciam diretamente na dinâmica da vegetação dos ambientes florestais. Esse resultado observado corrobora o observado por Seidelmann et al. (2016), que avaliando os efeitos direto do microclima e da diversidade de espécies arbóreas na decomposição de serapilheira em florestas, observaram que as variáveis topografia, microclima e riqueza de espécies explicaram uma fração importante das variações na taxa de decomposição da serapilheira.

\section{Conclusões}

O estoque e os teores de nutrientes da serapilheira acumulada em Floresta Estacional Semidecidual foram influenciados pelo tipo da pedoforma, a variação do gradiente topográfico e a estação do ano. Os maiores estoques de serapilheira ocorrem na pedoforma convexa, na estação seca e os maiores teores de $\mathrm{K}^{+}$e $\mathrm{Mg}^{2+}$ ocorrem na serapilheira acumulada nas porções inferiores das pedoformas. Já os teores de carbono foram influenciados apenas pela estação do ano como maiores teores na estação chuvosa.

A decomposição da serapilheira acumulada ocorre de maneira diferenciada em função da pedoforma, do gradiente topográfico e da estação do ano, cujos maiores valores foram observados na pedoforma convexa e na estação chuvosa.

\section{Referências}

APONTE, C.; GARCÍA, L. V.; MARAÑÓN, T. Tree species effect on litter decomposition and nutrient release in Mediterranean oak forests changes over time. Ecosystems, Austrália, v. 31, n.7, p. 1204-1218, 2012.

BORÉM, R. T.; RAMOS, D. P. Variação estacional e topográfica de nutrientes na serapilheira de um fragmento de Mata Atlântica. Cerne, Lavras, v. 8, n. 2, p. 42-59, 2002.

CUNHA, G. M. et al. Biomassa e estoque de carbono e nutrientes em Florestas Montanas da Mata Atlântica na região Norte do estado do Rio de Janeiro. Revista Brasileira de Ciência do Solo, Viçosa, v. 33, n. 5, p. 1175-1185, 2009.

CUNHA NETO, F. V. et al. Acúmulo e decomposição da serapilheira em quatro formações florestais. Ciência Florestal, Santa Maria, v. 23, n. 3, p. 379-387, 2013.

DINIZ, A. R. et al. Frações da matéria orgânica do solo em plantios clonais de seringueira em regiões costeiras do Brasil. Revista de la Facultad de Agronomía, La Plata, Buenos Aires, v. 114, n.1, p. 106-114, 2015.

FERREIRA, M. L. et al. Litter fall production and decomposition in a fragment of Secondary Atlantic Forest of São Paulo, SP, Southeastern Brazil. Revista Árvore, Viçosa, v.38, n.4, p.591$600,2014$.

GARTNER, T. B. et al. Decomposition dynamics in mixed-species leaf litter. Oikos, v. 104, n. 2, p. 230-246, 2004.

GODINHO, T. O. et al. Biomassa, macronutrientes e carbono orgânico na serapilheira depositada em trecho de Floresta Semidecidual Submontana, ES. Scientia Forestalis, Piracicaba, v. 41, n. 97, p. 131-144, 2013.

GODINHO, T. O. et al. Quantificação da biomassa e nutrientes na serapilheira acumulada em um trecho de Floresta Estacional Semidecidual Submontana, ES. Cerne, Lavras, v. 20, n. 1, p. 1120, 2014.

HEAL, O.W. et al. Plant litter quality and decomposition: an historical overview, In: Driven by Nature: plant litter quality and decomposition. Walingford: CAB International, 1997. 409 p. 
HÄTTENSCHWILER, S. Effects of tree species diversity on litter quality and decomposition. In: Forest diversity and function. Springer, Berlin, Heidelberg, 2005. p. 149-164.

HOMEIER, J. et al. Tree Diversity, Forest Structure and Productivity along Altitudinal and Topographical Gradients in a Species-Rich Ecuadorian Montane Rain Forest. Biotropica, Washington, v. 42, n. 2, p. 140-148, 2010.

INSTITUTO BRASILEIRO DE GEOGRAFIA E ESTATÍSTICA. Manual Técnico da Vegetação Brasileira: Sistema fitogeográfico Inventário das formações florestais e campestres, técnicas e manejo de coleções botânicas, procedimentos para mapeamentos. IBGE 2a Edição. Rio de Janeiro, 2012. $271 \mathrm{p}$.

JESUS NASCIMENTO, A. F. et al. Produção e aporte de carbono, nitrogênio e fósforo na serapilheira foliar do Parque Nacional Serra de Itabaiana. Ciência Florestal, Santa Maria, v. 28, n. 1, p. 35-46, 2018.

MACHADO, D. V. Atributos indicadores da dinâmica sucessional em fragmento de Mata Atlântica na região do Médio Vale do Paraíba do Sul, Pinheiral, Rio de Janeiro. 2011. 119 f. Dissertação (Mestrado em Ciências Ambientais e Florestais) - Universidade Federal Rural do Rio de Janeiro, Seropédica. 2011.

MACHADO, D. L. et al. Ciclagem de nutrientes em diferentes estágios sucessionais da Mata Atlântica na bacia do Rio Paraíba do Sul, RJ. Bioscience Journal, Uberlândia, v. 31, n. 4, p. 12221237, 2015.

MENDONÇA, V. M. M. et al. Aporte de serapilheira sobre diferentes condições geomorfológicas em Floresta Estacional Semidecidual Submontana, RJ. Revista Floresta, Curitiba, v. 3, 10 p., 2019.

MENEZES, C. E. G. et al. Aporte e decomposição da serapilheira e produção de biomassa radicular em florestas com diferentes estágios sucessionais em Pinheiral, RJ. Ciência Florestal, Santa Maria, v. 20, n. 3, p. 439-452, 2010.

PORTELA, R. C.Q.; SANTOS, F. A. M. Produção e espessura da serapilheira na borda e interior de fragmentos florestais de Mata Atlântica de diferentes tamanhos. Revista Brasileira de Botânica, São Paulo, v.30, n.2, p.271-280, 2007.

PROTIL, C. Z. et al. Variação sazonal e redistribuição de bioelementos de quatro espécies arbóreas em três tipologias florestais da Floresta Atlântica do Paraná. Floresta, Curitiba, v.39, n.3, p.699-717, 2009.

REZENDE, C. P. et al. Litter deposition and disapperance in Brachiaria pastures in Atlantic forest region of South Bahia, Brazil. Nutrient Cycling in Agroecosystems, Netherlands, v. 54, n. 2, p. 99-112, 1999.

RIGGS, C. E. et al. Contrasting effects of plant species traits and moisture on the decomposition of multiple litter fractions. Oecologia, Berlin, v. 179, n. 2, p. 573-584, 2015.

SANTONJA, M. et al. Climate change effects on litter decomposition: intensive drought leads to a strong decrease of litter mixture interactions. Plant and Soil, v. 393, n. 1-2, p. 69-82, 2015.

SANTOS, G. L. et al. Padrões da Regeneração Natural na Região de Mar de Morros, Pinheiral-RJ. Floresta e Ambiente, Seropédica, v. 24, 11 p., 2017.

SCHEER, M. B. Decomposição e liberação de nutrientes da serapilheira foliar em um trecho de Floresta Ombrófila Densa Alivial em regeneração, Guaraqueçaba (PR). Revista Floresta, Curitiba, v. 38, n. 2, p. 253-266, 2008.

SCORIZA, R. N.; PIÑA-RODRIGUES, F. C. M. Influência da precipitação e temperatura do ar na produção de serapilheira em trecho de Floresta Estacional em Sorocab̧a, SP. Revista Floresta, Curitiba, v. 44, n. 4, p. 687 - 696, 2014. 
SEIDELMANN, K. N. et al. Direct vs. microclimate-driven effects of tree species diversity on litter decomposition in young subtropical forest stands. PloS one, v. 11, n. 8, p. e0160569, 2016.

SOUZA, E. D. et al. Biomassa microbiana do solo em sistema de integração lavoura-pecuária em plantio direto, submetido a intensidades de pastejo. Revista Brasileira de Ciênica do Solo, Viçosa, v.34, p.79-88, 2010.

TEDESCO, M. J.; GIANELlO, C.; BISSANI, C. A. Análise de solo, plantas e outros materiais. 2. Ed. Porto Alegre: Departamento de Solos, UFRGS, p. 177-188. 1995.

THOMAS, R. J.; ASAKAWA, N. M. Decomposition of leaf litter from tropical forage grasses and legumes. Soil Biology and Biochemistry, Oxford, v. 25, n. 10, p. 1351- 1361, 1993.

TROEH, F. R. Landform equations fitted to contour maps. Soil Science Society American Journal, New York, v. 263, p. 616-27, 1965.

VITAL, A. R. T. et al. Produção de serapilheira e ciclagem de nutrients de uma Floresta Estacional Semidecidual e zona ripária. Revista Árvore, Viçosa, v. 28, n. 6, p. 793-800, 2004. 